\title{
Water resources management in Beijing using economic input-output modeling
}

\author{
Li Wang, Heather L. MacLean, and Barry J. Adams
}

\begin{abstract}
To support more sustainable development of a region, decision support tools must consider local and global systems level impacts on the economy, environment, and society. Through the development and application of "economic input-output water resources" models for Beijing, China for the years 1985, 1990, and 1992, historical trends related to the economy structure and its water use are investigated. The study finds that the economy of Beijing and water use are highly concentrated in agriculture and heavy industry, but this intensive water use is indirectly reflected in the production of most other goods and services throughout the economy because of the interrelationships among various sectors of the economy. In spite of progress during the time period observed (e.g., between 1985 and 1990 the output of the economy doubled, but water consumption increased only $12 \%$ partly because of a significant increase in the price of water in 1988) and given the seriousness of water resources issues in the region, it is critical that future regional development make progress toward a more water-efficient economic system.
\end{abstract}

Key words: water resources planning, urban water management, input-output modeling.

Résumé : Des outils d'aide à la décision doivent tenir compte des impacts des systèmes « locaux » et "globaux » sur l'économie, l'environnement et la société afin de supporter un développement plus durable d'une région. Les tendances historiques de la structure de l'économie et de son utilisation de l'eau sont étudiées par le développement et l'utilisation de modèles économiques des entrées-sorties des ressources en eau pour Beijing, en Chine, pour les années 1985 , 1990 et 1992. L'étude montre que l'économie de Beijing et son utilisation de l'eau sont très concentrées sur l'agriculture et l'industrie lourde mais, en raison des interrelations entre les secteurs économiques, cette utilisation intensive de l'eau se reflète indirectement dans la production de la plupart des autres biens et services de cette économie. Malgré le progrès réalisé durant la période à l'étude (c.-à-d. entre 1985 et 1990, le rendement de l'économie a doublé, mais la consommation d'eau n'a augmenté que de $12 \%$, probablement en raison d'une augmentation importante du prix de l'eau en 1988). Étant donné la gravité des questions touchant les ressources en eau dans la région, il est important que le futur développement régional progresse vers un système plus économique et plus efficace de gestion de l'eau.

Mots clés : planification des ressources en eau, gestion des eaux en milieu urbain, modélisation des entrées-sorties.

[Traduit par la Rédaction]

\subsection{Introduction}

Strategies that allow for more sustainable development of a region require that the endowment of natural resources in the region and the impacts of economic development on the environment and human health be considered in parallel with the development. These concerns have brought the need for coordinating the consideration of resource use, the environment, and economic development to the forefront. This requires interdisciplinary and timely systems level information for decision making that considers the economy-wide

Received 07 April 2004. Revision accepted 18 March 2005.

Published on the NRC Research Press Web site at

http://cjce.nrc.ca on 9 August 2005.

L. Wang. XCG Consultants Ltd., 2620 Bristol Circle, Suite 300, Oakville, ON L6H 6Z7, Canada.

H.L. MacLean and B.J. Adams. ${ }^{1}$ Department of Civil Engineering, University of Toronto, 35 St. George St., Toronto, ON M5S 1A4, Canada.

Written discussion of this article is welcomed and will be received by the Editor until 31 December 2005.

${ }^{1}$ Corresponding author (e-mail: adams@civ.utoronto.ca). implications of development. In this work, we focus on the regional water resources of Beijing, China. The water resources of the region are directly linked to its economic development; water demand being a function of economic development and associated standards of living, and in contrast, water supply and water quality concerns are able to significantly impair development.

Since 1978 when the People's Republic of China adopted economic reforms and open-door policies the country has made considerable progress in economic development with an average annual increase in the gross domestic product (GDP) of 10\% (SSB 1986-2000). The pre-reform era in China was marked by forced industrialization with emphasis on heavy industry. These policies resulted in dominance of heavy industry; repetitive industrial structures; underdevelopment of urban infrastructure, high tech, and service industries; and little attention to the comparative advantages of the geographic location of the country and resource endowment (Chang 1998). From an environmental perspective, the overall result of the development has been compromised environmental conditions and a resource intensive industrial structure.

Beijing, the capital and second largest city of China (with a Municipality population in the year 2000 of 12.78 million 
(Municipality 2002)), continues to experience rapid growth and industrial expansion. This development has brought many benefits for its citizens but has also resulted in negative impacts on the environment and public health. Although other environmental issues are prominent in the Beijing region, recent attention has focused on water resources. Beijing has serious degradation of surface and groundwater resources (Xie et al. 1991). In 1995, the gross volume of water in Beijing was 3.96 billion cubic metres (BCM), where the surface water supply was $1.25 \mathrm{BCM}$, making up $32 \%$ of the total, while the groundwater supply was $2.71 \mathrm{BCM}$ or $68 \%$ of the total. There has been severe overexploitation of the groundwater resources, and the water table under the city has fallen by approximately $60 \mathrm{~m}$ since 1965 (Yan 1999). The average annual volume of wastewater discharged is 1.26 $\mathrm{BCM}$, most of which is discharged without treatment (Yan 1999). The region is suffering from severe water shortage and water pollution, which some studies have described as a “crisis" (Kwang 2000; People's Daily 2001b; China Online 2001). Chang (1998) puts forth the issue of water shortage as the most serious constraint to sustainable growth of Beijing. The volume of water resources available per capita for the city of Beijing is $300 \mathrm{~m}^{3} / y e a r(1 / 8$ the national average and $1 / 29$ the world average). Chang (1998) provides an overview of the water supply system of Beijing. There has been an increasing demand for water in Beijing because of the rapid economic growth, increasing urban population, and an improving standard of living. The disparity between water supply and demand has become increasingly pronounced, and the water shortage is estimated to reach $2.85 \mathrm{BCM}$ in year 2020 (Yan 1999). On the water quality side, in 1990, $90 \%$ of the water resources of Beijing were considered polluted to some degree (Xie et al. 1991). Although water resources management in the region has been attracting government attention, which is commended since progress has been made, prevailing systems for decision-making have tended to focus on end-of-pipe measures and on the lack of necessary integration of economic, social, and environmental factors at the policy, planning, and management levels.

To facilitate future development that is more sustainable, the situation in the Beijing region (as well as that in many areas worldwide) requires the application of more holistic analyses. Since Beijing is still in a stage of rapid development and in the midst of a transition from a command to a market economy, its necessary institutional, legal, and political reforms are continually evolving. Therefore, it is an opportune time for the region to integrate water management and policy with economic development and to approach water management problems from both upstream and downstream directions to improve the situation in the future.

Decision support for more sustainable economic development planning requires information on the economy-wide implications on resources, the environment, and the public health of the development. Economic input-output (EIO) analysis is a systems level economic model that allows for the incorporation of the economy, resources, and the environment in the model, facilitating analyses for this decision support. The EIO analysis was first developed by Wassily Leontief in the 1930s (Leontief 1966) and allows for the quantitative analysis of interrelationships among the sectors in the economy and includes direct as well as indirect (supplier) impacts.

This study takes steps to address the above needs by developing, implementing, and applying EIO based models for Beijing that include water resources data. We implement the economic input-output water resources (EIO water resources) models for Beijing. The models are based on EIO tables, which are augmented with sectoral water resources (water production and use and wastewater discharge) data. Although EIO models have certain limitations (see Miller and Blair (1985) and Joshi (2000)), they are one of the few modeling techniques to disclose economy-wide trends in resource utilization and production. Therefore, the models allow us to investigate economy-wide (at the regional level) implications of economic development strategies on resources and the environment. We develop EIO water resources models based on the EIO tables and water resources data for the years 1985, 1990, and 1992, because much can be learned by observing development trends over time, particularly in the case of a region, such as Beijing, which is undergoing rapid development. Comparison of models and outputs from different time periods provides insights into the structural, price, and (or) demand driven changes within the rapidly developing Beijing economy, as well as changes in water use and discharge patterns and efficiency. Finally, we develop insights regarding future development of the region to alleviate water shortages and in support of pollution prevention, through analyzing four development scenarios. We compare our results (where appropriate) with those of an earlier EIO study of water resources of Beijing by Xie et al (1991). The insights generated from the present study suggest that EIO water resources models have the potential to provide support for more sustainable management of economic development and associated water resources in the Beijing region but improved data collection, verification, and availability are critical to increased utility and acceptance of these models.

\subsection{Economic input-output modeling}

The EIO analysis provides a method for the systematic analysis of the inter-industry transactions in an economy. Economic activities are divided into a number of production or industrial sectors. The basis of EIO analysis (and of the present work) is the EIO total requirements matrix. The matrix (often called table) has the intersectoral flows of products as its coefficients from producers to purchasers (usually measured in monetary units but sometimes in physical units) for a particular time period (usually a year). The matrix columns consist of the coefficients representing the inputs from each sector into the sector at the head of the column, while rows consist of coefficients that represent the distribution (to other sectors) of the outputs of the sector at the head of the row. In addition, sales to purchasers that are external to the industrial sectors (e.g., government, households, and export) are included in the matrix. The demands of these sectors are termed final demand. Inputs not from other industrial sectors (e.g., labor, capital) are grouped and termed value added. Miller and Blair (1985) provide a good review of EIO theory and applications. Since the EIO model considers the entire economy, its application eliminates many of the difficulties 
associated with narrow boundaries and resulting suboptimal decisions in systems level environmental analyses (Joshi 2000). The EIO analysis at the most basic level allows one to investigate the economic implications throughout the economy of a change in final demand for product or service of a particular sector. Since sectors are all interdependent (they purchase goods and services from many other sectors), there are resulting implications in the entire economy resulting from these indirect effects.

Many countries, including China, the USA, and Canada, compile national and regional EIO tables at regular time intervals. The EIO framework has previously been extended to study resources management and to account for pollution generation and abatement associated with economic activity. Leontief (1970) was one of the first who explicitly integrated emission rates of pollutants into an EIO table. Other examples include Carter and Ireri (1970), Miller and Blair (1985), Hendrickson et al. (1998), and Joshi (2000). Wang (2002) provides additional review of EIO modeling and environmental linkages.

In China, EIO research originated in the 1960s, but no official research was permitted during the Cultural Revolution (1966-1976) as the techniques were considered to be capitalistic. However, there has been considerable EIO research since that time, which is documented (up to the late 1980s) in an English language summary by Polenske and Chen (1991). Examples of more recent work include Hao (1991), Li (1991), Yuan (1998), Lei (1998), and Chen (2000). Included in these works are several resources-based applications. Xie et al. (1991) (in Polenske and Chen 1991) developed an EIO model for Beijing and then incorporated the urban water and wastewater systems into the model. The model was used to investigate the structure of water use and disposal systems in Beijing and additionally to analyze effects of changes in the structure of final demand on regional water resources and pollution using two development scenarios. Since the work has similarities to the current work, we briefly discuss the primary results of the study and compare them to our results where possible. However, because of differences in the study methods and limitations attributed to the summary nature of the results presented by Xie et al. (1991), only a limited comparison (presented in Sect. 5) is possible.

\subsection{Method: Development of water resources economic input-output model}

Although we develop and apply the EIO water resource models for Beijing, the method is generalizable to any region that maintains EIO tables and the required water resources data. The framework for the water resources inputoutput model is presented in Table 1 . The EIO model in Table 1 can be viewed as a material balance sheet classified according to the industrial sectors. The input-output balance among the industrial sectors is represented by

$$
X_{i}=\sum_{j=1}^{n} z_{i j}+T_{i}+U_{i}+Y_{i}, \quad(i=1,2, \ldots, n)
$$

where the total output of sector $i, X_{i}$, is comprised of the sums of all inter-industry sales of $i$ sector, its sales to the wa- ter and wastewater treatment sectors, and its sales to final demands. The technical coefficient (or direct input coefficient) for sector $j$ is denoted by $a_{i j}$, and it represents the direct input from sector $i$ per unit of output of sector $j$. The direct input coefficient for the water sector is denoted by $a_{i}^{t}$ and represents the direct input from a production sector $i$ per unit of output of the water production and supply sector. The direct input coefficient for the wastewater treatment sector is denoted by $a_{i}^{u}$ and is the input from production sector $i$ per unit of wastewater treated. These direct coefficients are defined as follows:

$$
\begin{array}{ll}
a_{i j}=\frac{z_{i j}}{X_{j}}, & (i, j=1,2, \ldots, n) \\
a_{i}^{t}=\frac{T_{i}}{W}, & (i=1,2, \ldots, n) \\
a_{i}^{u}=\frac{U_{i}}{M}, & (i=1,2, \ldots, n)
\end{array}
$$

In an EIO system, these coefficients are assumed to be constant; i.e., when output of sector $j$ is doubled, the input from $i$ to $j$ is doubled. Therefore, the EIO framework operates under an assumption of constant returns to scale (Miller and Blair 1985). Equation [1] can be rewritten as follows (in matrix form) by substituting in the expressions for the technical coefficients given in eq. [2] to [4]:

$$
\mathbf{X}=A \mathbf{X}+A^{t} \mathbf{W}+A^{u} \mathbf{M}+\mathbf{Y}
$$

Based on the addition of the water production and supply sector to the EIO table, the corresponding input-output balance for water use is as follows:

$$
W=\sum_{j=1}^{n} F_{j}+G+K
$$

where $W$ represents the total output from the water production and supply sector, $F$ is the consumption of water by the industrial sectors, $G$ is the consumption of water by the water production and supply sector itself, and $K$ is the final demand for the sector.

The direct water input coefficient for the production sectors is denoted by $b_{j}^{f}$. It represents the volume of water consumed per unit of output of sector $j\left(X_{j}=X_{i}\right.$ based on EIO convention).

[7] $\quad b_{j}^{f}=\frac{F_{j}}{X_{j}}, \quad(j=1,2, \ldots, n)$

Similarly, the direct water input coefficient for the water sector is denoted by $b^{g}$ and represents the amount of water consumed by the water production and supply sector per unit of output from the sector itself; i.e.,

$$
b^{g}=\frac{G}{W}
$$

These direct water coefficients can be used to analyze the direct sectoral water use patterns in the region. Later, in eq. [15], we develop the total water use coefficients, which include both direct and indirect water uses. 
Table 1. Framework for water resources economic input-output model.

\begin{tabular}{|c|c|c|c|c|c|c|}
\hline & & $\begin{array}{l}\text { Production } \\
\text { sectors }(j)\end{array}$ & $\begin{array}{l}\text { Water production } \\
\text { and supply }\end{array}$ & $\begin{array}{l}\text { Wastewater } \\
\text { treatment }\end{array}$ & & \\
\hline Input & Output & $1,2, \ldots, n$ & $n+1$ & $n+2$ & Final demand & Total output \\
\hline & 2 & $z_{i j}$ & $T_{i}$ & $U_{i}$ & $Y_{i}$ & $X_{i}$ \\
\hline & $n$ & & & & & \\
\hline Water production and supply & $n+1$ & $F_{j}$ & $G$ & & $K$ & $W$ \\
\hline Intermediate input & & $I_{j}$ & $\mathrm{I}_{\mathrm{W}}$ & $I_{\mathrm{WW}}$ & & \\
\hline Value added & & $\mathrm{V}_{j}$ & $\mathrm{~V}_{\mathrm{W}}$ & $V_{\mathrm{WW}}$ & & \\
\hline Total input & & $X_{j}$ & $W$ & $M$ & & \\
\hline
\end{tabular}

Note: $E$, total water discharge; $F_{j}$, consumption of water by production sector $j ; G$, consumption of water by water production and supply sector; $I$, production sector $1,2, \ldots, n ; I_{j}$, intermediate input to production sector $j ; I_{\mathrm{W}}$, intermediate input to water production and supply sector; $I_{\mathrm{Ww}}$, intermediate input to wastewater treatment sector; $J$, production sector, $1,2, \ldots, \mathrm{n} ; K$, final demand for water production and supply sector; $M$, total amount of wastewater treated; $P_{j}$, water discharged by production sector $j ; S$, water discharged by the final demand sectors; $T_{i}$, value of input from production sector $i$ to water production and supply sector; $U_{i}$, value of input from production sector $i$ to wastewater treatment sector; $V_{j}$, value added for production sector $j$; $V_{\mathrm{W}}$, value added for water production and supply sector; $V_{\mathrm{WW}}$, value added for wastewater treatment sector; $W$, total output of water production and supply sector; $X_{i}$, total output of production sector $i ; X_{j}$, total input to production sector $j$ (= $X_{i}$ based on EIO convention); $Y_{i}$, final demand for production sector $i$; and $z_{i j}$, value of input from production sector $i$ to sector $j$.

Incorporating the expressions in eqs. [7] and [8], eq. [6] can also be rewritten in matrix form:

$$
\mathbf{W}=B^{f} \mathbf{X}+B^{g} \mathbf{W}+\mathbf{K}
$$

Thus, water uses can be expressed as coefficients based on the sector production levels. After computing the production levels, the total quantity of water used is obtained by multiplying by the relevant water input coefficients.

We also add to the EIO matrix a row of coefficients representing wastewater quantities generated by the various production sectors. The input-output balance for water discharge is given by

$$
E=\sum_{j=1}^{n} P_{j}+S
$$

where $E$ is the total discharge of wastewater which is the sum of the discharges of wastewater from all of the sectors $(P)$ and from the final demands $(S)$. The wastewater discharged from the water sector would conceptually be included in eq. [10], however, because of this amount being very small and that no data are available to support this term, we have not included it in our formulation. The direct wastewater discharge coefficient for production sector $j, c_{j}^{p}$, represents the volume of wastewater resulting from the production of one unit of output from sector $j$.

$$
\text { [11] } \quad c_{j}^{p}=\frac{P_{j}}{X_{j}}, \quad(j=1,2, \ldots, n)
$$

The direct coefficient can be used to identify primary wastewater sources and provides guidance on decision making for pollution prevention. The total wastewater discharge coefficient representing both direct and indirect discharges is developed later in eq. [16].

Incorporating the expression for direct wastewater discharge in eq. [11], eq. [10] can be written in matrix form:

$$
\mathbf{E}=C^{p} \mathbf{X}+\mathbf{S}
$$

Since the quantity of wastewater discharged is a function of the production levels, once these levels are determined, the total amount of wastewater discharged from each sector can be obtained by multiplying by the relevant discharge coefficients. Summing across all the sectors yields the economy-wide quantity of wastewater discharged.

We designate alpha $(\alpha)$ as the proportion of wastewater that is treated $(0 \leq \alpha \leq 1)$. The total amount of wastewater treated $(M)$ is the product of $\alpha$ and the total amount of wastewater discharged $(E)$. Therefore, $M=\alpha E$. The overall input-output balance is presented in a matrix form by grouping eqs. (5), (9) and (12) together as follows:

$$
\left[\begin{array}{ccc}
A & A^{t} & A^{u} \alpha \\
B^{f} & B^{g} & 0 \\
C^{p} & 0 & 0
\end{array}\right]\left[\begin{array}{c}
X \\
W \\
E
\end{array}\right]+\left[\begin{array}{c}
Y \\
K \\
S
\end{array}\right]=\left[\begin{array}{c}
X \\
W \\
E
\end{array}\right]
$$

and the determinant system of equations is given by

$$
\left|\begin{array}{l}
X \\
W \\
E
\end{array}\right|=\left|\begin{array}{ccc}
I-A & -A^{t} & -A^{u} \alpha \\
-B^{f} & I-B^{g} & 0 \\
-C^{p} & 0 & 0
\end{array}\right|^{-1}\left|\begin{array}{c}
Y \\
K \\
S
\end{array}\right|=L\left|\begin{array}{c}
Y \\
K \\
S
\end{array}\right|
$$

The form of eq. [14] is similar to $\mathbf{X}=(I-A)^{-1} \mathbf{Y}$, the equation with the conventional Leontief inverse, $(I-A)^{-1}$. The term $L$ can be referred to as the extended Leontief inverse (Chen 2000). Equation [14] is used to determine the total output from all industrial sectors, $X$, total water use, $W$, and total wastewater discharge, $E$, in accordance with given final demands $Y, K$, and $S$. Thus, eq. [14] establishes the relationship between the production and water and wastewater sectors.

One notable element of the EIO method is the incorporation, not just of direct sectoral implications, but indirect implications as well through the designation of indirect and total coefficients. For example, water is consumed both directly and indirectly by an industrial sector. The food pro- 
cessing sector directly consumes water in its production processes. Recall that the direct water input coefficient, $b_{j}^{f}$, represents the volume of water consumed per unit of output from sector $j$, in this example, the food processing sector. However, the sector also depends on inputs from other industrial sectors such as agricultural products, electricity, and chemicals that use water as input into their processes. The amount of water consumed by the first tier supplier production sectors is referred to as the "first" indirect water input. The "second" indirect water input can be deduced in the same way (water required by second tier suppliers) and so on. The total water input coefficient is the sum of all the direct and indirect water input coefficients and is calculated as follows (revised from Chen 2000):

$$
\text { [15] } \quad T_{f}=B^{f}(I-A)^{-1}
$$

These direct and total water input coefficients can be used to analyze the water use patterns in the region of interest and predict the economy-wide effects of specific economic development scenarios on water use.

Similarly, the direct wastewater discharge coefficient defined previously in eq. [11], $c_{j}^{p}$, is the amount of wastewater per unit of output from sector $j$. The total wastewater discharge coefficient, $T_{p}$, is the sum of the direct and indirect wastewater discharges per unit of output from sector $j$. The total wastewater discharge coefficient, $T_{p}$, can be calculated as follows (revised from Chen 2000):

[16] $T_{p}=C^{p}(I-A)^{-1}$

The wastewater discharge coefficients can be used to identify primary wastewater sources, provide information to formulate guidance on pollution prevention, and predict impacts of development on water quality, incorporating the systems level approach that includes direct and indirect impacts.

\subsection{Application of the economic input- output water resources model to Beijing}

We construct three EIO water resources models for Beijing (for the years 1985, 1990, and 1992). The EIO tables include the city of Beijing and its suburbs, as shown in Fig. 1. We use the Beijing EIO tables available from the Beijing statistical yearbooks, which are the most recent and publicly available, and complete IO data available for which we were able to locate the corresponding year of water resources data. These are a 116-sector table for the year 1992 (SSB 1996) and six-sector tables for the years 1985 (SSB 1987) and 1990 (SSB 1995). The 116-sector table for the year 1992 is the most recent table published at this level of disaggregation. Since Beijing experienced significant economy-wide reforms during the time period 1986-1990 (SSB 1986-1996), we use the six-sector tables for 1985 and 1990 to compare the changes during that period, which are of particular interest from both economic and water resources points of view. Although a more recent six-sector table is available (for year 2000), we were unable to use this table in our research because of the lack of publicly available water data for the corresponding year. The EIO tables are in prices of producers in the applicable currency (yuan) of the year. The six-sector tables include the industrial sectors: agriculture, industry, construction, transportation and communication, commerce, and other services. The industry sector includes industries such as coal mining, food processing, textile products, chemicals, and paper and paper products. The sector other services consists primarily of nonmaterial production sectors. The sectors of the 116-sector table are shown in Wang (2002). The level of detail provided by EIO analysis is highly dependent on the aggregation level of the EIO tables employed. Although the tables with six sectors are highly aggregated and do not provide detailed information, they still provide insights for water resources planning, particularly resulting from the comparison of the tables of the different years.

We develop the water resources EIO models using the above Beijing EIO tables, augmented with water use, water discharge, and wastewater treatment data that we gathered from various publicly available databases. The water resources data were collected from the Beijing statistical yearbooks (SSB 1986-1996) and the Beijing Environmental Master Plan Studies report (World Bank 1996). Some water and wastewater activities are already accounted for in the six-sector tables, conceptually when we add additional sectors, existing sectors should be disaggregated. However, in our models, since only six sectors of the economy are being considered, the subtraction of the water resources and wastewater sectors from other services would result in no discernible difference in the final results. Furthermore, the subtraction would have necessitated obtaining the raw economic make and use tables from the Chinese government, which was not possible. As well, the method that we employed is relatively standard practice in environmental input-output analysis (e.g., Hendrickson et al. 1998).

At the 116-sector level of aggregation, water production and supply is one of the 116 sectors of the model; therefore, it is not necessary to augment the EIO table with this sector. However, for consistency with the other EIO models, the water production and supply sector was converted from monetary terms (presented in the original matrix) into physical units $\left(\mathrm{m}^{3}\right)$. These conversions were based on prices for water obtained for the agriculture, industry, and service sectors. In the cases where water prices could not be obtained, the average price of water for that year $\left(0.21 \mathrm{yuan} / \mathrm{m}^{3}\right)$ (Hou 2001) was employed. Unfortunately, a complete set of water discharge and wastewater treatment data at this level of disaggregation was not available and therefore is not included in the 116-sector model. However, at the six-sector level, all water and wastewater data were available (one of our primary justifications for using these smaller models), providing for the complete model.

The data used to develop the coefficients for each sector for the water production and use sector include the amount (in physical units) of water traded as a commodity through the services of water production and supply and the monetary value of sector output. However, some industrial sectors pump surface water directly from water bodies or exploit groundwater from unregulated private wells. The amount of water consumed in the latter cases is not included in the EIO water resources models, which likely impacts the results in some sectors. However, to include these water inputs, records of water use through a regulated metering system 
Fig. 1. Map of study area (CHS 1999).

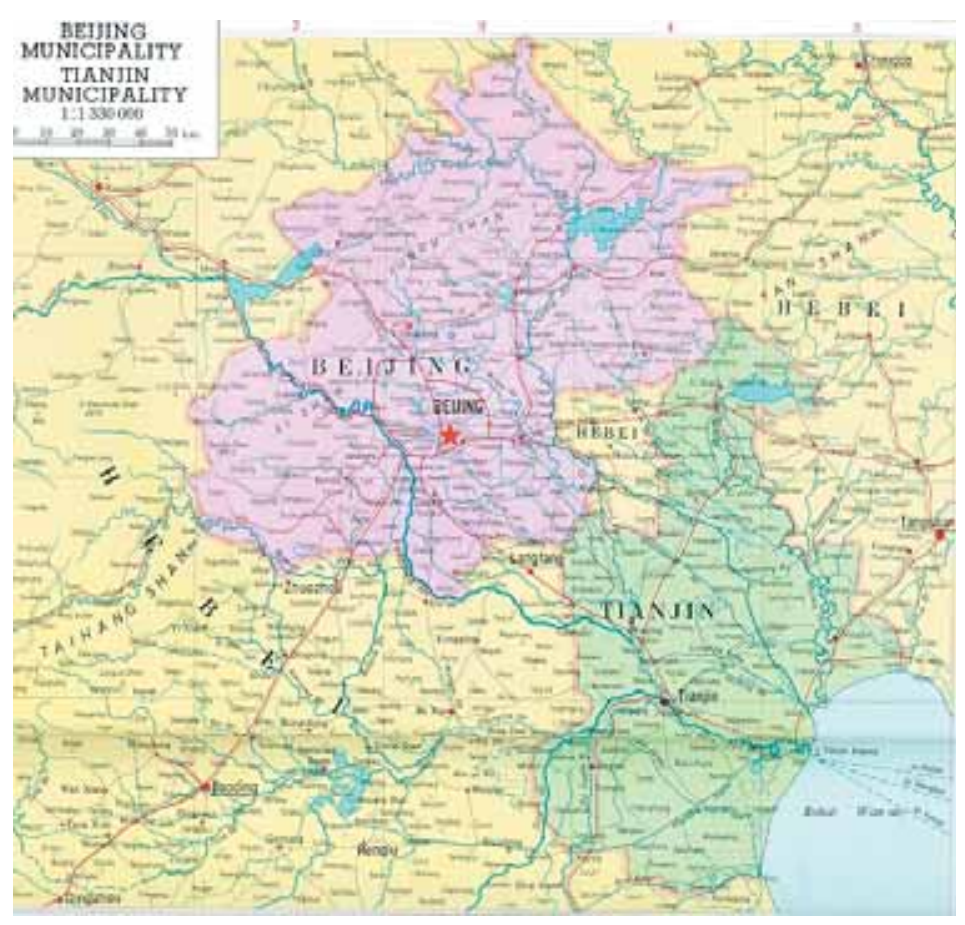

would be required (not the practice at this time). In addition, data reporting reuse and (or) recycling of wastewater were not available in a format consistent with the EIO tables (e.g., the definition of industrial sectors was not consistent with those in the EIO tables) and therefore could not be included in the models.

Based on the modeling results, the water use patterns and main wastewater discharge sources in the region are evaluated with a focus on future development strategies. Since the 1985 and 1990 six-sector models are reasonably comparable (same data source, same sectors, etc.), we are able to analyze the economic development and resulting water resources patterns in Beijing that occurred during that time period by comparing the model outputs. The basic components of change in the water use and wastewater discharge of the economy are associated with the basic EIO equation, $\mathbf{X}=(I-A)^{-1} \mathbf{Y}$ (Miller and Blair 1985), and its multiplication by the water resources vectors, $\boldsymbol{B}^{f}$ and $\boldsymbol{C}^{p}$ (to obtain the water use or wastewater discharge as a result of final demand). These components are

1. changes in the technical coefficients in the economic matrix $(I-A)^{-1}$ (due to changes in the structure of the economy),

2. changes in total output of the sectors,

3. changes in the water use coefficients $\left(\mathrm{m}^{3}\right.$ per 1000 yuan of sector output), and

4. changes in prices.

Since the 116-sector 1992 model is not directly comparable to the more aggregate models but offers more detailed information about water use, our analysis of water use focuses also on results from this model. Since the aggregation of the model developed by Xie et al. (1991) most closely matches with that of our 116-sector model, we compare some basic results of these two models. We also develop and evaluate three scenarios for future economic development using the 116-sector model.

\subsection{Results and discussion}

\subsection{Changes in the structure of the Beijing economy, 1985-1990}

Economic input-output tables for countries such as the United States and Canada, whose economies have been quite stable in their development for some time, show great inertia, generally exhibiting only small changes in their coefficients from one time period to the next. In contrast, since Beijing experienced significant economy-wide reforms during the time period 1986-1990 (SSB 1986-1996) we find large changes in the 1985 and 1990 structural (technical coefficient) matrices. There is also the potential of changes in data collection or other methods (e.g., sector definitions) that may have occurred with the EIO tables, but we could not find evidence of such changes. Tables 2 and 3 show the direct input coefficients for 1985 and 1990 for the two sectors, exhibiting the largest changes during the time period; agriculture and industry. The agriculture sector relied more on inputs from other sectors and less on those from within the agriculture sector in 1990 than in 1985. There are significant increases in the direct inputs to the agriculture sector from the other sectors (ranging from 50\% to almost $400 \%$ increases). Only the value-added coefficient has decreased. For the industry sector, there has been less change during the time period, but as well, except for inputs from the transportation and communication sector and value added, all direct coefficients have increased. In particular, industry is receiving substantially more input from agriculture and commerce. These changes are due to changes in the economic structure itself, technologies employed in the sectors, etc. As noted 
Table 2. Comparison of six-sector model direct input coefficients $\left(A_{i j}\right)$ for agriculture sector for 1985 and 1990.

\begin{tabular}{llll}
\hline Sector & 1985 & 1990 & \% change 1985-1990 \\
\hline Agriculture & 0.160521 & 0.098952 & -38 \\
Industry & 0.137116 & 0.209963 & +53 \\
Construction & 0.000226 & 0 & - \\
Transportation and communication & 0.012923 & 0.022695 & +76 \\
Commerce & 0.011743 & 0.025097 & +114 \\
Other services & 0.006375 & 0.031257 & +390 \\
Other & 0.003479 & - & - \\
Value added & 0.655905 & 0.612037 & -7 \\
\hline
\end{tabular}

Note: Number of significant figures is not indicative of the accuracy of the value but is based on the number of figures reported in the EIO tables.

Table 3. Comparison of six-sector model direct input coefficients $\left(A_{i j}\right)$ for industry sector for 1985 and 1990.

\begin{tabular}{llll}
\hline Sector & 1985 & 1990 & \%change 1985-1990 \\
\hline Agriculture & 0.038434 & 0.054951 & +43 \\
Industry & 0.484404 & 0.544042 & +12 \\
Construction & 0.000695 & 0 & - \\
Transportation and communication & 0.02705 & 0.024705 & -9 \\
Commerce & 0.037556 & 0.052354 & +39 \\
Other services & 0.024428 & 0.030932 & +27 \\
Other & 0.002331 & - & - \\
Value added & 0.379166 & 0.293016 & -23 \\
\hline
\end{tabular}

above, such structural changes in the economy are one component of the water use and wastewater discharge changes associated with these two periods.

\subsection{Water use in the Beijing region, 1985-1992}

The distributions of water use by sector for 1985 and 1990 are shown in Figs. $2 a$ and $2 b$, respectively, based on the results of the six-sector models. The total output (where noted in the text corresponds to the EIO definition of "sum of intermediate output and final demand less imports") of the regional economy increased from 59.2 billion yuan in 1985 to 128.0 billion yuan in 1990 (more than $100 \%$ increase). The total consumption of water increased only $12 \%$, from 3.662 BCM in 1985 to $4.167 \mathrm{BCM}$ in 1990. The profiles of water use are very similar for both years, as shown in the figures. The water use of Beijing (and its economy) is highly concentrated in agriculture and heavy industry. Among all water users, the agriculture sector is the largest user, accounting for about $60 \%$ of the total. This is consistent with the earlier result of Xie et al. (1991) (62\% for the time period 1983-86). Agricultural water use increased from 2.2 BCM to $2.4 \mathrm{BCM}$ from 1985 to 1990 . Industry consumed $13 \%$ of total water, and final demands accounted for $18 \%$ to $21 \%$ of consumption. Industrial water use increased from 663 million cubic metres (MCM) to $875 \mathrm{MCM}$.

The similarity in the quantity of water used and its distribution among the sectors as discussed above belies the significant changes in sectoral water use during the time period. The EIO water resources models through the direct and indirect water use allow us to understand more clearly some of the differences in water use during this time period. We cal-
Fig. 2. (a) Distribution of water use in Beijing in 1985. (b) Distribution of water use in Beijing in 1990.
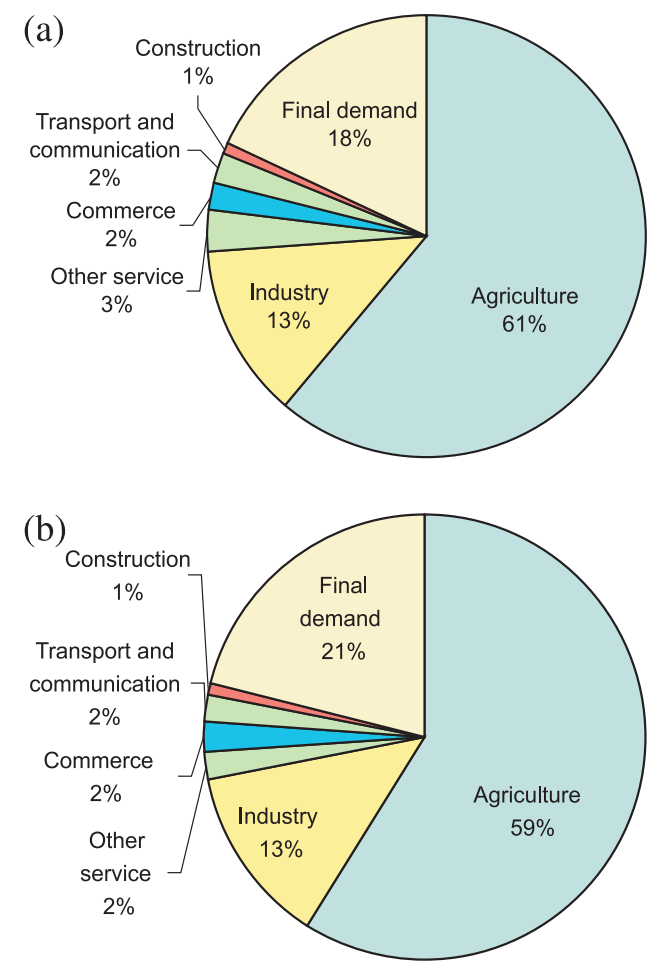

culate direct and total water input coefficients from the sixsector 1985 and 1990 models, as shown in Table 4. 
Table 4. Direct and total water input coefficients for the six-sector model ( $\mathrm{m}^{3}$ water per 1000 yuan output).

\begin{tabular}{|c|c|c|c|c|}
\hline \multirow[b]{2}{*}{ Sector } & \multicolumn{2}{|l|}{1985} & \multicolumn{2}{|l|}{1990} \\
\hline & $\begin{array}{l}\text { Direct water input } \\
\text { coefficient } b^{f}\end{array}$ & $\begin{array}{l}\text { Total water input } \\
\text { coefficient } T_{f}\end{array}$ & $\begin{array}{l}\text { Direct water input } \\
\text { coefficient } b^{\mathrm{f}}\end{array}$ & $\begin{array}{l}\text { Total water input } \\
\text { coefficient } T_{f}\end{array}$ \\
\hline Industry & 19 & 130 & 12 & 85 \\
\hline Construction & 5 & 89 & 4 & 58 \\
\hline Transportation and communication & 31 & 88 & 26 & 66 \\
\hline
\end{tabular}

The results presented in Table 4 show the enormous water use of the agriculture sector indicated by the sector having the largest total and direct water input coefficients (total coefficients are $1046 \mathrm{~m}^{3}$ per 1000 yuan output for 1985 and 404 for 1990). As indicated by the ratio of direct to total water input coefficients, almost all this water is directly used by the agriculture sector itself. It should be noted that the 1985 and 1990 values in Table 4 are in 1985 and 1990 yuan, respectively. Initially, we considered using consumer price indices or other methods to examine prices in more detail in this comparison, however, China only adopted the consumer price index as a major price index in 2000, and the retail price index used prior to that time is not applicable for this work.

The industry sector is the second highest water user but is a distant second to agriculture. The low ratio of direct to total water input coefficients indicates that the majority of the water use of the industry sector is indirect (by suppliers to the sector). All the remaining sectors also have low ratios of direct to total water input coefficients. The majority of water use is by suppliers to the listed sectors. These sectors consume significant amounts of raw materials and depend on intermediate products for inputs into their operations.

The Beijing Environmental Master Plan Studies reports the amount of industrial water use per 1000 yuan (currently equivalent to about US\$120) of industrial output for 1985 and 1990; i.e., the direct water input coefficients (World Bank 1996). The amount for 1985 was $21.5 \mathrm{~m}^{3}$ per 1000 yuan and for 1990, $12.3 \mathrm{~m}^{3}$ per 1000 yuan (World Bank 1996). This data match well with our EIO water resources model results for the industry sector of $19 \mathrm{~m}^{3}$ per 1000 yuan for 1985 and $12 \mathrm{~m}^{3}$ per 1000 yuan for 1990 . We were unable to locate an independent data source that could be used to verify our models; the comparison with World Bank (1996) is necessary but not sufficient for verification. It may be expected that the results of our study match closely to those of World Bank (1996) because some of our model data were coming from this source, however, the particular data compared were obtained from SSB (1986-1996), not World Bank (1996).

Table 4 also shows that the direct and total water use coefficients for all sectors decreased over the time period 1985 to 1990 . The percentage decreases in the total water input coefficients ranging from $26 \%$ for the transportation and communication sector to $61 \%$ for the agriculture sector. Similarly, direct water use coefficient decreases ranging from $16 \%$ for transportation and communications to $60 \%$ for agriculture. The World Bank (1996) also presents corresponding figures that show a decreasing tendency. The explanation for this decrease likely involves several factors. One factor was a significant increase in the price of water in Beijing that occurred in 1988. At that time, the price of water used for agriculture and industry more than doubled (Fichot and Hou 2001). Water use would be expected to decrease with a price increase. At least in part associated with this price increase, but also with technological developments, there likely were improvements in production processes leading to more efficient water use. Other possible explanations include a shift in the economy structure toward sectors with lower water requirements, such as high-tech and tertiary industries, and potentially increased use of unmetered water supplies.

We calculate the water use multipliers (indirect water use coefficient divided by direct water use coefficient) to examine whether there were significant changes in the proportion of indirect versus direct water use by the sectors during the time period. Table 5 shows the water use multipliers for 1985 and 1990. Overall, the multipliers did not change markedly. Those for industry and other services increased, while those for the other sectors decreased. The largest changes were in the construction and other services sectors.

\subsection{Water use results for the 1992 116-sector model}

In this section we report the water use results for the 1992 116-sector EIO water resources model. The extended Leontief inverse, direct water input, and total water input coefficients are calculated by applying eqs. 14, 7, and 15, respectively. Wang (2002) shows the entire set of direct and total water input coefficients for all the economic sectors. The interpretation of these direct and total coefficients leading to insights on the pattern of water use is discussed below. Since the 116-sector aggregation is the closest match in our study to the aggregation level of the model of Xie et al. (1991), we compare the results of the two studies where possible.

- Total water use for 1992 is 4.5 BCM, an increase of $8 \%$ from the 1990 value of 4.167 BCM. The total output increased from 128.0 billion yuan in 1990 to 213.1 billion yuan in 1992 (66\% increase).

- Agriculture remains the largest water user, continuing as in previous years to account for $60 \%$ of total water consumption in Beijing. Also similar to the six-sector model results, the majority of agricultural water use is direct water use as indicated by the similarity of the direct and total 
Table 5. Water use multipliers for Beijing for 1985 and 1990 (from six-sector tables).

\begin{tabular}{lrr}
\hline Sector & 1985 & 1990 \\
\hline Agriculture & 0.22 & 0.18 \\
Industry & 5.80 & 6.30 \\
Construction & 16.17 & 12.66 \\
Transportation and communication & 1.83 & 1.51 \\
Commerce & 4.01 & 3.02 \\
Other services & 5.58 & 7.90 \\
\hline
\end{tabular}

water input coefficients (e.g., for the grain crop cultivation sector, the direct water input coefficient is $18.0 \mathrm{~m}^{3}$ water per 1000 yuan output whereas the total water input coefficient is $25.4 \mathrm{~m}^{3}$ water per 1000 yuan output).

- Industry continues to be a large water user. Industrial sectors with the largest water input coefficients include linen products, leather and leather products, sawmills and fabricated wood products, electricity, steam and hot water production and supply, and household chemicals. Similarly, Xie et al. (1991) found that the main water users included electricity generation, chemicals, metallurgy, textiles, and paper-making. We found that sectors such as electronic and communication equipment manufacturing and transportation and communication have relatively low water input coefficients.

- Comparing direct and total water use, the majority of sectors in the 116-sector model have total water input coefficients that are at least twice their direct water input coefficients (of the 98 material production sectors in our model, 74 were at least twice as high). Some sectors such as food production, paper and paper products, chemical industry, and metal products have total water input coefficients that are many times greater than their direct coefficient. For example, the largest water use multipliers (indirect coefficient divided by direct coefficient) are those for sugar refining (108.01) and slaughter houses and meat packing (68.07). Within the food processing category, which contains 10 food processing sectors (including the above two sectors), the average multiplier is 34.8. This is mostly because of the high agricultural water use by inputs into food processing sectors. The chemical industry, machinery, electrical machinery and equipment, and electronic and communication equipment sectors also have high multipliers. Xie et al. (1991) reports that more than $50 \%$ of the products in their EIO model have total water use coefficients that are at least twice as high as the direct coefficient with some being up to 50 times higher. The sectors with high multipliers have significant indirect water demand, resulting from the consumption of raw materials by the sectors and their strong links with intermediate products. Such insights are often ignored in conventional water resources studies, while EIO modeling enables a more complete investigation of direct and indirect water use in industrial sectors throughout the regional economy.

\subsection{Distribution of wastewater discharge}

As only the six-sector models report wastewater discharge, we report results based on these models. The total
Fig. 3. (a) Distribution of wastewater discharge for Beijing in 1985. (b) Distribution of wastewater discharge for Beijing in 1990.
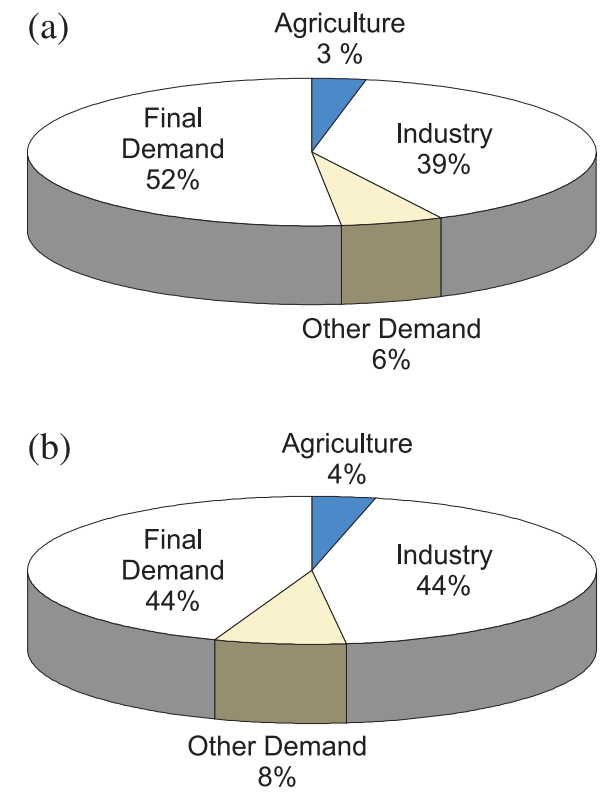

amount of wastewater discharged (untreated) decreased from 970 MCM for 1985 to 900 MCM for 1990, a 7\% decrease even though water use increased by $12 \%$ and the economy output increased substantially during this time period. Since inflow and infiltration could have impacted wastewater discharge results for the time period, we examined rainfall data and found similar data for both 1985 and 1990 (611 and $662 \mathrm{~mm}$, respectively), indicating that this was not responsible for the differences observed. The water and wastewater data are not unreasonable; data on wastewater are selfreported (the source of the data (SSB 1986-1996) does not indicate whether the wastewater plant operator or the discharger is doing the reporting) and subject to error. The distributions of wastewater discharge in 1985 and 1990 are shown in Figs. $3 a$ and $3 b$, respectively.

Among all sectors, the largest amount of wastewater discharged is from final demand, accounting for 52\% in 1985 and $44 \%$ in 1990. Domestic wastewater is the main source of this discharge. Wastewater discharged from the industry sector accounted for 39\% in 1985 and 44\% in 1990. The amount of discharge from agriculture is relatively small, which is not surprising because of evapotranspiration, infiltration, and runoff (unlikely to be metered). Agricultural production in Beijing has increased steadily over the years, even though the cultivated area has decreased with rapid economic and urban development (World Bank 1996). This increase in production has been aided by an increase in fertilizer and pesticide use in efforts to attain agricultural production goals. Adverse environmental impacts of the agriculture sector are significant. The use of these fertilizers and pesticides has resulted in agriculture being a significant nonpoint source of water pollution, and water quality has deteriorated because of runoff from suburban areas. In addition, there is no regular monitoring of wastewater discharged from agriculture, which may explain the reason for the above percentage of wastewater discharge from agriculture being relatively small. 
Table 6. Direct and total wastewater discharge coefficients for six sectors ( $\mathrm{m}^{3}$ wastewater per 1000 yuan output).

\begin{tabular}{|c|c|c|c|c|}
\hline \multirow[b]{2}{*}{ Sector } & \multicolumn{2}{|l|}{1985} & \multicolumn{2}{|l|}{1990} \\
\hline & $\begin{array}{l}\text { Direct wastewater } \\
\text { coefficient } c^{p}\end{array}$ & $\begin{array}{l}\text { Total wastewater } \\
\text { coefficient } T_{p}\end{array}$ & $\begin{array}{l}\text { Direct wastewater } \\
\text { coefficient } c^{p}\end{array}$ & $\begin{array}{l}\text { Total wastewater } \\
\text { coefficient } T_{p}\end{array}$ \\
\hline Industry & 11 & 25 & 5 & 30 \\
\hline Construction & 2 & 18 & 1 & 20 \\
\hline Transportation and communication & 5 & 16 & 4 & 19 \\
\hline
\end{tabular}

We calculate the direct and total wastewater discharge coefficients for the years 1985 and 1990 using the six-sector models (see Table 6). The wastewater discharge decreased relative to the industrial output; i.e., the direct wastewater discharge coefficient ranged from $7-13 \mathrm{~m}^{3}$ per 1000 yuan in 1985 and from 5-7 $\mathrm{m}^{3}$ per 1000 yuan in 1990 (as in Table 4, it should be noted that price differences impact these results and so results presented should be interpreted carefully). The total wastewater discharge coefficients for the industry sector are larger than those for the other sectors. Similarly, there is a significant difference between the direct and total wastewater discharge coefficients for the industry sector and those for all others. Changes in the above coefficients from 1985 to 1990 are less significant than the corresponding changes in the water input coefficients.

\subsection{Alternative development scenarios}

To demonstrate potential application of the EIO water resources models, we examine impacts on water use and wastewater discharge of potential development through the evaluation of simplified alternative development scenarios using first the 1990 six-sector model and then the 1992 116sector model. These scenarios are only meant to illustrate the technique, not to represent expected future developments.

A "what if" scenario based on 1990 conditions is implemented for the six-sector model. It assumes a $15 \%$ increase (1917 million yuan) in final demand for the construction industry (People's Daily 2001a). This scenario is based on current and sustained long term urban building boom of Beijing. Using $\Delta \boldsymbol{Y}$ for the vector of changes in final demand, then $\Delta X$, the vector of resulting changes in outputs, is found as $\Delta \boldsymbol{X}=(I-A)^{-1} \Delta \boldsymbol{Y}$. Table 7 presents the results for this development scenario.

Table 7 shows that the greatest economic effect of this increase in final demand for construction is associated with the industry sector, with a total output increase of 2827 million yuan. The construction sector follows with a total output increase of 1918 million yuan. The total new output effect throughout the regional economy, obtained by summing the elements in $\Delta \boldsymbol{X}$, is 5625 million yuan. The increase in final demand in the construction sector results in increased demand for water and increased wastewater discharges. There would be an increase of $110.6 \mathrm{MCM}$ ( $2.7 \%$ increase) in water use and an increase of $19.92 \mathrm{MCM}$ (4\% increase) in wastewater discharge throughout the economy associated with the increase in final demand for construction. However, the construction sector itself uses only a tiny fraction of this water: the agriculture sector, followed by the industry sector are responsible for the vast majority of this water use. Scenarios such as this illustrate the interdependencies throughout the economy and again emphasize how imperative it is that the agriculture and industry sectors in the region become more water-resource efficient.

The 116-sector EIO model can be used to estimate future water demands based on alternative economic development scenarios. The results could then be used to inform decision and policy making. We considered three scenarios as follows:

Scenario 1: a $10 \%$ increase in final demands for all sectors. This scenario is based on an average GDP growth rate of $10 \%$ over the past two decades (SSB 1986-2000, 1998),

Scenario 2: a $10 \%$ increase in final demands for all sectors, and a $20 \%$ decrease in the agricultural water use coefficient (reflective of the previous scenario, but also reflecting recent declines in agricultural sector water use), and

Scenario 3: a 10\% decrease in final demand for the agricultural and major heavy industry sectors, and a $10 \%$ increase in final demand for light industry, transportation, commerce, and service sectors (reflecting a changing industry mix).

We report the total changes in water use throughout the economy for the three scenarios. As expected, the first two scenarios result in increased water use (increases of $8.7 \%$ and $7.5 \%$, respectively). These increases are almost equivalent to the $10 \%$ increase in final demand. The $20 \%$ decrease in the agricultural water use coefficient can be seen as the difference between the percentages for the two scenarios. The result of the third scenario is particularly interesting as the shift in demand from heavy industry to lighter and (or) higher tech industries results in a substantial decrease in water use $(15 \%)$.

\subsection{Summary and conclusions}

The Beijing of today reflects its past history of development, its economy, and water use being highly concentrated in agriculture and heavy industry. Agriculture is by far the largest user, accounting for approximately $60 \%$ of total water use. Almost all this water is used directly by the sector itself. The industry and construction sectors rank a distant second and third, respectively, in water use. These and other sectors have low direct water use but high indirect water use (the water is used by supplier industries, in many cases, agricultural inputs). The economic structure of Beijing is irratio- 
Table 7. Total output increase and water use and wastewater discharge associated with a $15 \%$ increase in final demand for construction.

\begin{tabular}{llll}
\hline Sector & $\begin{array}{l}\text { Total output } \\
\text { (million yuan) }\end{array}$ & $\begin{array}{l}\text { Water use } \\
\text { (MCM) }\end{array}$ & $\begin{array}{l}\text { Wastewater } \\
\text { discharge (MCM) }\end{array}$ \\
\hline Agriculture & 178 & 60.9 & 0.85 \\
Industry & 2827 & 33.0 & 15.01 \\
Construction & 1918 & 8.1 & 2.76 \\
Transportation and communication & 173 & 4.6 & 0.78 \\
Commerce & 288 & 2.9 & 0.22 \\
Other services & 241 & 1.1 & 0.30 \\
Total & 5625 & 110.6 & 19.92 \\
\hline
\end{tabular}

nal considering its positive attributes and its water resources endowment and associated crisis.

During the period 1985 to 1990 , the total output of economy of Beijing doubled but total water consumption increased just $12 \%$, with an associated decrease in the water use coefficients for all sectors (a likely factor was a doubling of the price of water in 1988). Wastewater discharged decreased by 7\% during this time period. Between 1990 and 1992 , the economy output increased by $66 \%$ and water use increased by $8 \%$. Evaluating potential future scenarios with the models elucidates the interrelationships among the sectors of the economy, and it is imperative that the region develop more water-resource efficient agriculture and industry sectors. For example, a 15\% increase in final demand for construction results in the highest total sector output from the industry sector (not the construction sector) and the highest water use (153 MCM) in the agriculture sector (compared with only $10 \mathrm{MCM}$ for the construction sector).

Although it appears progress has been made during the time period observed, given the seriousness of water issues in the region (e.g., Beijing has an available per capita volume of water resources of only $1 / 29$ th the world average.), and that much of the production is exported to other countries of the world, future development should focus on modifying the existing economy and developing new industries based on its comparative advantages (e.g., location, skilled workforce, resources in reasonable supply, etc.) and limitations of water resources. The levels of outputs of sectors with intensive water consumption (high water input coefficients) and heavy pollution discharges should be examined carefully and steps taken to improve the situation. Sectors with lower water demands and lower pollutant discharges should continue to be developed.

The results of this study suggest that, from a water resources perspective, the outputs of sectors such as food production, paper and paper products, chemical industry, and metal products should be reduced, while electronics, communication, bio-engineering and new pharmaceuticals, and public services should be developed. Additionally, as discussed by Chang (1998) much of the processed product of heavy industries of Beijing is not consumed locally, thereby making the case even stronger for restructuring away from resource intensive industries. As early as 1980, proposals to restructure away from water and energy intensive industries were put forward by the Central Party Secretary Office of the city of Beijing and by researchers at the Chinese Academy of Sciences, resulting in limited progress (Chang 1998), however, far more effort is needed to move toward a more sustainable industrial structure. Sustainable water resources management is broader than conventional resource management. Integration, coordination, and a systematic approach to economic development considering the environment are needed to move toward more sustainable water resources management in the Beijing region.

This study makes some progress in developing economywide water resources models for Beijing. The models developed have the potential to offer decision support to assist in the identification of beneficial economic structures that take into account water resources endowments and the environment in the future development of the region. However, water resources represent only one aspect of the many resource and environmental issues that must be accounted for in regional development.

Although there are benefits in the systems level insights that are obtained by extending the EIO framework in the manner detailed in this work, there are limitations of this study, as noted earlier, attributable to the EIO method, to the extension of the model to include water resources, and to the large extent to data issues. Of the general limitations of EIO methods (Joshi 2000), the primary ones impacting this study are the limitations of aggregation level of EIO models, that economies of scale in production and substitution effects are neglected in the modeling process (Miller and Blair 1985). In addition, it is necessary to look beyond industrial sectors, to examine specific processes and quality of outputs, when examining water and wastewater issues. Data limitations have been a major constraint in the work; both the availability and the quality. However, with improved data collection, quality, and verification, EIO analysis can offer valuable insights because of its inclusion of economy-wide direct and indirect effects, and that it can be integrated with many economic-environmental studies.

\section{Acknowledgements}

The authors wish to gratefully acknowledge the financial support of the Canadian International Development Agency, the Natural Sciences and Engineering Research Council of Canada and the University of Toronto.

\section{References}

Carter, O., and Ireri, D. 1970. Linkage of California-Arizona input-output models to analyze water transfer pattern in applications of input-output analysis. Edited by A.P. Carter and A. 
Brody. North-Holland Publishing, Amsterdam, The Netherlands. pp. 139-168.

Centre for Human Settlements (CHS). 1999. University of British Columbia. Available from http://www.chs.ubc.ca/china/index.html [accessed 29 September 2003].

Chang, S. 1998. Beijing: perspectives on preservation, environment, and development. Cities, 15(1): 13-25.

Chen, X. 2000. Shanxi water resources input-occupancy-output table and its application in Shanxi Province of China. In Proceedings of the 13th International Conference on Input-Output Techniques, Macerata, Italy, 21-25 August 2000. Available from http://www.iioa.org/conf/conferences.html [accessed 27 July 2005]

China Online. 2001. China faces long-term water shortages [online]. Available from http://www.chinaonline.com/industry/ environmental [accessed 3 September 2001].

Fichot, B., and Hou, E. 2001. Beijing watershed report card [online]. Available from http://www.chs.ubc.ca [accessed 20 March 2001].

Hao, J. 1991. Application of an energy input-output table for agriculture. China Statistical Publishing House, Beijing, People's Republic of China. [In Chinese.]

Hendrickson, C., Joshi, S., and Lave, L. 1998. Economic inputoutput models for environmental life-cycle assessment. Environmental Science and Technology, 32(7): 184-191.

Hou, E. 2001. Nine dragons, one river: the role of institutions in developing water pricing policy in Beijing, People's Republic of China. M.A. thesis, School of Community and Regional Planning, The University of British Columbia, Vancouver, B.C.

Joshi, S. 2000. Product environmental life-cycle assessment using input-output techniques. Journal of Industrial Ecology, 3(2): 95-120.

Kwang, M. 2000. Beijing taps may dry up in 5 years. Straits times (Singapore), 8 January 2000.

Lei, M. 1998. Input-output accounting for natural resourcesenergy-environment. In Proceedings of the 12th International Conference on Input-output Techniques, New York, N.Y., 18-22 May 1998. Available from http://www.iioa.org/conf/conferences. html [accessed 27 July 2005]

Leontief, W. 1966. Input-output economics. Oxford University Press, New York, N.Y.

Leontief, W. 1970. Environmental repercussions and the economic structure: an input-output approach. The Review of Economics and Statistics, 2(3): 262-271.

Li, B. 1991. Application of the input-output techniques in chinese enterprises. China Statistical Publishing House, Beijing, People's Republic of China. [In Chinese.]
Miller, R., and Blair, P. 1985. Input-output analysis: foundation and extensions. Prentice Hall, New Jersey, N.Y.

Municipality of Beijing Population Data. 2002. Available from http://www.demographia.com/db-beijing-ward.htm [accessed 14 June 2002].

People's Daily. 2001a. Economic index of major Chinese regions in 2000: Beijing, 3 November 2001.

People's Daily 2001b. ESCAP predicts 7.8 percent GDP growth for China, 4 April 2001.

Polenske, K.R., and Chen, X. (Editors). 1991. Chinese input-output research from a western perspective. Chinese Economic Planning and Input-output Analysis. Oxford University Press, Oxford. pp. 1-23.

State Statistical Bureau (SSB). 1986-1996. Beijing statistical yearbook. China Statistical Publishing House, Beijing, People's Republic of China. [In Chinese.]

State Statistical Bureau (SSB). 1986-2000. Beijing statistical yearbook. China Statistical Publishing House, Beijing, People's Republic of China. [In Chinese.]

State Statistical Bureau (SSB). 1987. Beijing input-output table of 1985. China Statistical Publishing House, Beijing, People's Republic of China. [In Chinese.]

State Statistical Bureau (SSB). 1995. Beijing input-output table of 1990. China Statistical Publishing House, Beijing, People's Republic of China. [In Chinese.]

State Statistical Bureau (SSB). 1996. Beijing input-output table of 1992. China Statistical Publishing House, Beijing, People's Republic of China. [In Chinese.]

Wang, L. 2002. Sustainable water resources management in the Beijing-Tianjin region, China. M.Appl.Sc. thesis, Department of Civil Engineering, University of Toronto, Toronto, Ont.

World Bank. 1996. Beijing environmental master plan studies. Beijing Municipal Environmental Protection Bureau, Beijing, People's Republic of China.

Xie, M., Nie, G., and Jin, X. 1991. Application of input-output model to the Beijing urban water-use system. Chinese economic planning and input-output analysis. Edited by K.R. Polenske and X. Chen. Oxford University Press, Oxford, U.K. pp. 239253.

Yan, C. 1999. History of Beijing's water resources (shui hui jing hua). Water Resources Press, Beijing, People's Republic of China. [In Chinese.]

Yuan, X. 1998. Environmental input-output model and its analysis on solid waste management sector. Transactions of Nonferrous Metals Society of China, 9(2): 412-416. 